\title{
Improvement of Hemolysis in Muscle Phosphofructokinase Deficiency by Restriction of Exercise
}

\author{
Hideki Toyoda, Tsutomu NaKase*, Makoto TomeoKu*, Koichi Morita*, Masami Kato*, \\ Tetsuya Murata**, Akira Ono***, Masamichi KuwaJIMA*** and Norio Kono****
}

A 29-year-old woman with muscle phosphofructokinase (PFK) deficiency had exercise intolerance, painful cramps, elevation of muscle enzyme levels in the serum and compensated hemolysis. After the restriction of exercise, the creatine kinase level and indirect bilirubin level decreased, and the reticulocyte count and haptoglobin level were normalized. It is suggested that the hemolysis which was accelerated by exercise was improved by restriction of exercise.

(Internal Medicine 35: 222-226, 1996)

Key words: erythrocyte, glycogenosis type VII

\section{Introduction}

Phosphofructokinase (PFK) catalyzes the conversion of fructose-6-phosphate to fructose-1,6-bisphosphate, a reaction that is a key step in the regulation of glycolysis. Muscle PFK deficiency, which was first described by Tarui et al in 1965 (1), is characterized by painful cramps with exercise, limitation of vigorous activity and increased hemolysis; the PFK activity is usually undetectable in muscle and decreased by almost half in erythrocytes. We report herein a case of muscle PFK deficiency and discuss the relationship between the hemolysis and daily exercise.

\section{Case Report}

The patient was a 29-year-old woman with normal growth and development. She was in good health and had two healthy children. Her parents were first cousins and her elder brother had died of icterus gravis neonatorum. Since her childhood she had experienced nausea on vigorous exercise, with vomiting and muscle pains. Pigmenturia after exercise was not noted. At the age of 17 years, she showed jaundice for the first time and was diagnosed with constitutional jaundice. In May 1989, jaundice was noted for the second time at a health examination. About three months later, she consulted a doctor at the outpatient clinic of our hospital for further evaluation of her jaundice. Informed consent was obtained prior to this study.

Physical examination: She was a well developed and well nourished woman in no acute distress. Her blood pressure was $130 / 80 \mathrm{mmHg}$, and pulse rate 74 beats $/ \mathrm{min}$. The skin and sclera showed an icteric tint. The chest was clear to auscultation and percussion. The heart showed a normal sinus rhythm with no murmurs or no evidence of cardiomegaly. The abdomen was soft and there was no organomegaly or palpable mass. There was no abnormality of the results of the neurological examination.

Laboratory data were as follows: Red blood cell (RBC) count, $4.16 \times 10^{6} / \mu \mathrm{l}$; hemoglobin $(\mathrm{Hb}), 15.3 \mathrm{~g} / \mathrm{dl}$; mean corpuscular volume (MCV), $109.8 \mathrm{fL}$; reticulocyte count, $2.6 \%$ with no morphological abnormalities of the erythrocytes; serum total bilirubin (T-bil), $5.6 \mathrm{mg} / \mathrm{dl}$ (indirect, $4.8 \mathrm{mg} / \mathrm{dl}$ ); aspartate aminotransferase (AST), $65 \mathrm{KU}$; lactic dehydrogenase (LDH), 431 Wrob.U; creatine kinase (CK), 3,705 IU/l (MM: 98.6\%, MB: $1.4 \%$ ); myoglobin, $3,220 \mathrm{ng} / \mathrm{ml}$; ammonia, 159 $\mu \mathrm{g} / \mathrm{dl}$; uric acid, $4.5 \mathrm{mg} / \mathrm{dl}$; haptoglobin, $40 \mathrm{mg} / \mathrm{dl}$ (normal 103 341); and erythropoietin, $58.3 \mathrm{mU} / \mathrm{ml}$ (normal 8-36). The bone marrow was hyperplastic with erythroid hyperplasia. The results of Ham test, sugar water test, and Coombs' test were all negative, and those of glucose tolerance tests, galactose tolerance test, and fasting glucagon test were all within normal limits. The findings of the chest radiogram and echocardiogram were normal. Gall bladder stones were detected by ultrasonography.

Semiischemic forearm exercise test (2) and bicycle-ergometer exercise test (3) were performed as described previously. Muscle biopsy of the left quadriceps was performed under

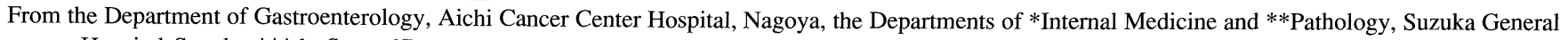
Hospital, Suzuka, ***the Second Department of Internal Medicine, Osaka University Medical School, Suita and ****the School of Allied Health Sciences, Faculty of Medicine, Osaka University, Toyonaka

Received for publication February 28, 1995; Accepted for publication October 17, 1995

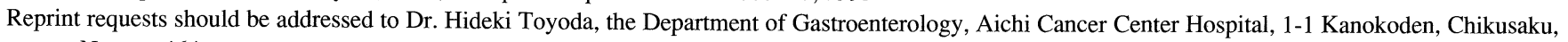
Nagoya 464 
spinal anesthesia, and samples were obtained for histopathologic studies using hematoxylin-eosin, histochemistry, electron microscopy, and biochemistry.

Biochemical analyses of erythrocytes and muscles were performed as described in previous publications (4-9). On the semiischemic forearm exercise test, the venous lactate concentration did not increase significantly and the venous ammonia concentration increased four fold. On the bicycle-ergometer exercise test, the ammonia concentration reached a peak (429 $\mu \mathrm{g} / \mathrm{dl})$ at the end of exercise and then declined rapidly, returning to the basal level $(81 \mu \mathrm{l} / \mathrm{dl})$ at 120 minutes after exercise. The uric acid concentration reached the maximum value $(12.5 \mathrm{mg} /$

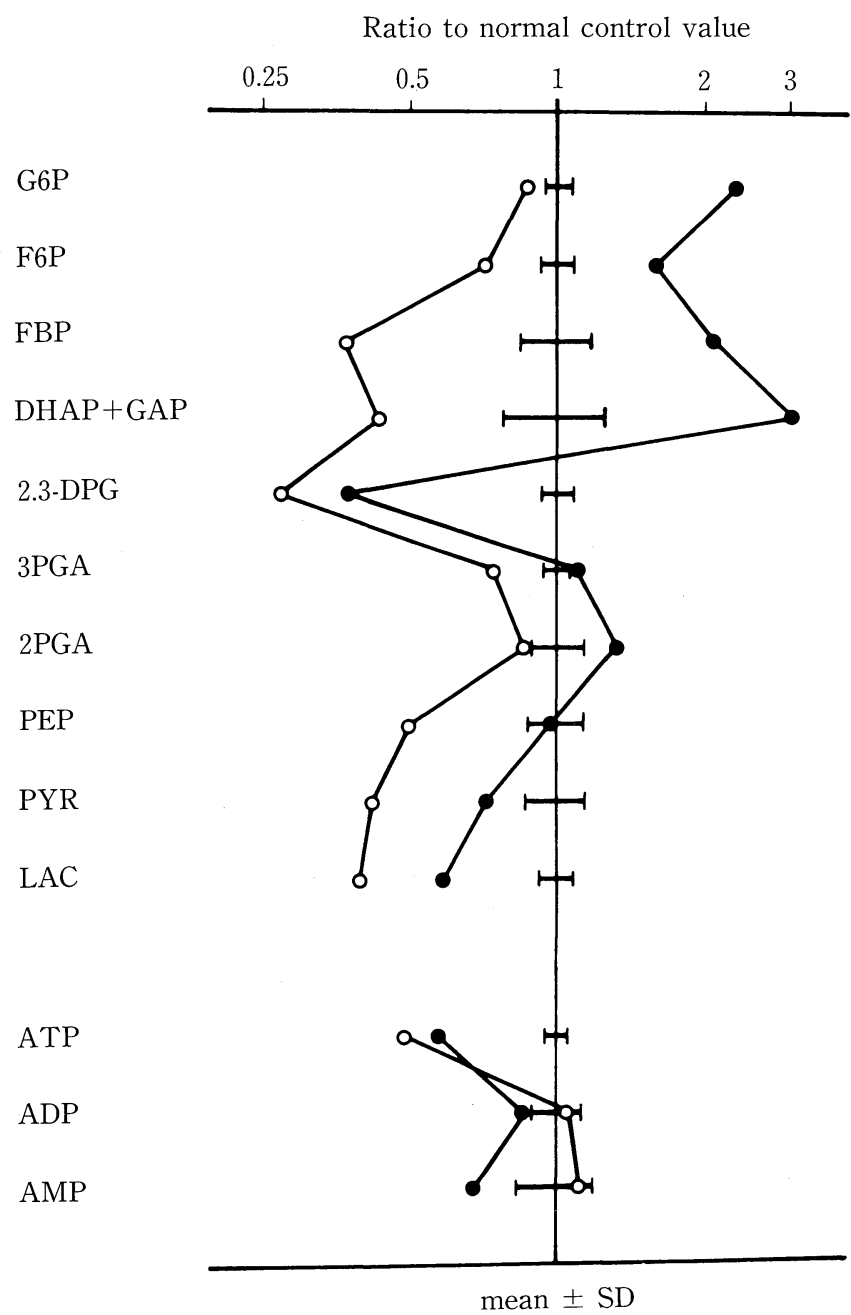

Figure 1. Concentrations of glycolytic intermediates and adenine nucleotides in erythrocytes at rest and after ergometric exercise. Blood samples were obtained before $(0)$ and after $(\bullet)$ exercise. G6P: glucose-6-phosphate, F6P: fructose-6-phosphate, FBP: fructose-1,6-bisphosphate, DHAP: dihydroxyacetone phosphate, GAP: glyceraldehyde-3-phospahte, 2,3-DPG: 2,3diphosphoglycerate, 3PGA: 3-phosphoglycerate, 2PGA: 2-phosphoglycerate, PEP: phosphoenopyruvate, PYR: pyruvate, LAC: lactate, ATP: adenosine triphosphate, ADP: adenosine diphosphate, AMP: adenosine monophosphate. dl) at 30 minutes, and remained high, at $12.0 \mathrm{mg} / \mathrm{dl}$, at 120 minutes after exercise.

In the examination of erythrocyte metabolism, the erythrocyte PFK activity was $41 \%$ of the normal control value. No quantitative abnormality could be detected in the other erythrocyte enzyme activities investigated, including those of hexokinase, glucosephosphate isomerase, pyruvate kinase, and lactate dehydrogenase. The concentrations (ratio to normal control value) of glycolytic intermediates and adenine nucleotides in erythrocytes at rest and after ergometric exercise are shown in Fig. 1. At rest, there were decreased ratios for glycolytic intermediates, especially for fructose-1,6-bisphosphate, 2,3diphosphoglycerate (2,3-DPG), lactate, pyruvate and dihydroxyacetone phosphate+glyceraldehyde-3-phosphatelevels. There was a decreased ratio for total adenosine nucleotides as well as adenosine triphosphate (ATP), while the levels of adenosine diphosphate (ADP) were normal. After exercise, the concentrations of intermediates of the first few steps of glycolysis were greatly increased.

In the evaluation of muscle metabolism, the muscle PFK activity was $0.3 \%$ of the normal control value (Table 1). Other enzyme activities were within normal limits. The concentrations of glycogen, glucose-6-phosphate and fructose-6-phosphate were increased to 4-5 times the corresponding values in normal controls. Electron microscopic examination of muscle disclosed accumulation of glycogen granules under the sarcolemma and between the myofibrils (Fig. 2).

The clinical course is summarized in Fig. 3. She was admitted three times to our hospital, and changed her occupation, first working as a kindergarten teacher, then an office worker, and

Table 1. Biochemical Analysis of Muscle Biopsy Specimen

\begin{tabular}{lcc}
\hline & Patient & $\begin{array}{c}\text { Controls } \\
\text { (mean } \pm \text { SD) }\end{array}$ \\
& & \\
\hline Concentrations of intermediates & & \\
Glycogen (mg/g muscle) & 41.0 & $11.4 \pm 4.2$ \\
Glucose-1-phosphate (n mol/g muscle) & 18 & 16,25 \\
Glucose-6-phosphate (n mol/g muscle) & 1,715 & $415 \pm 164$ \\
Fructose-6-phosphate (n mol/g muscle) & 415 & $79 \pm 26$ \\
Fructose-1,6-bisphosphate (n mol/g muscle) & 1 & $66 \pm 50$ \\
Dihydroxyacetone phosphate & & \\
+Glyceraldehyde-3-phosphate & 5 & $53 \pm 13$ \\
(n mol/g muscle) & \multicolumn{3}{c}{} \\
Activities of enzymes (U/g muscle) & 12.4 & $13.8 \pm 4.6$ \\
Phosphorylase, total & 3.1 & $4.9 \pm 5.4$ \\
Phosphorylase a & 9.3 & \\
Phosphorylase b & 0.47 & $0.59 \pm 0.15$ \\
Hexokinase & 0.1 & $33 \pm 12$ \\
Phosphofructokinase (PFK) & 105 & $119 \pm 22$ \\
Pyruvate kinase & 67 & $55.6 \pm 27.4$ \\
Phosphorylase kinase* & & \\
\hline
\end{tabular}

* One unit of phosphorylase kinase is defined as one activity forming unit of phosphorylase per minute. 


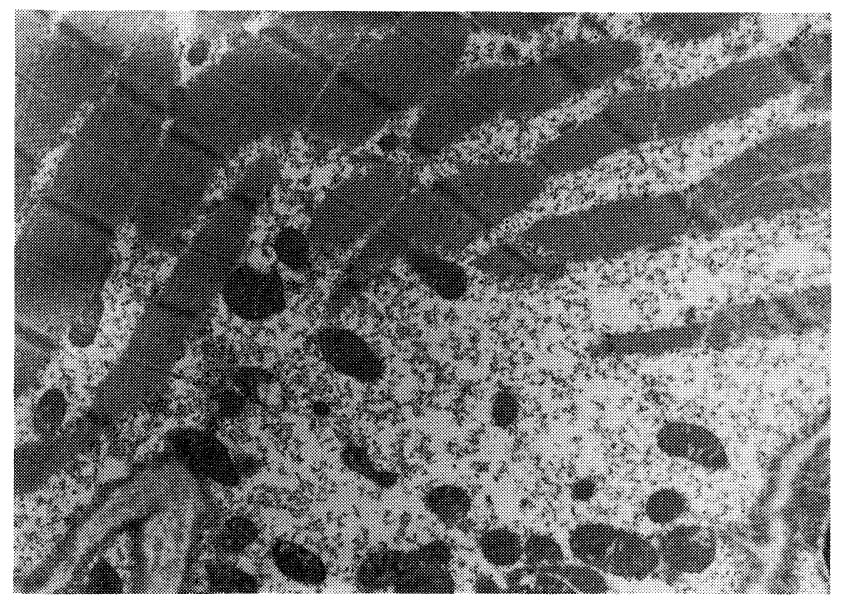

Figure 2. Electron micrograph showing accumulation of glycogen granules between myofibrils $(\times 8,000)$.

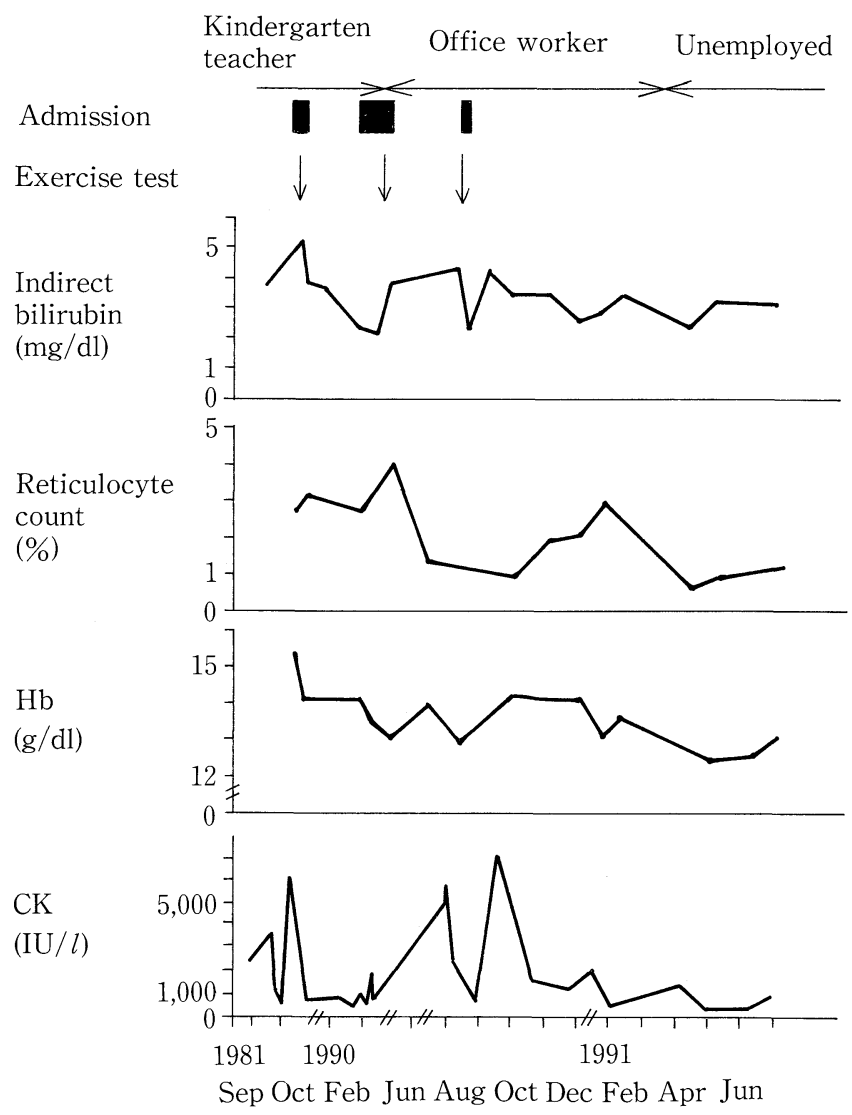

Figure 3. Clinical course.

finally unemployed. The CK levels varied markedly with the amount of daily exercise. After she became unemployed the CK levels were relatively stable and the reticulocyte count and haptoglobin level $(111 \mathrm{mg} / \mathrm{dl})$ normalized. The normalization of haptoglobin level after the restriction of exercise is suggestive of mild intravascular hemolysis. Figure 4 shows the mean

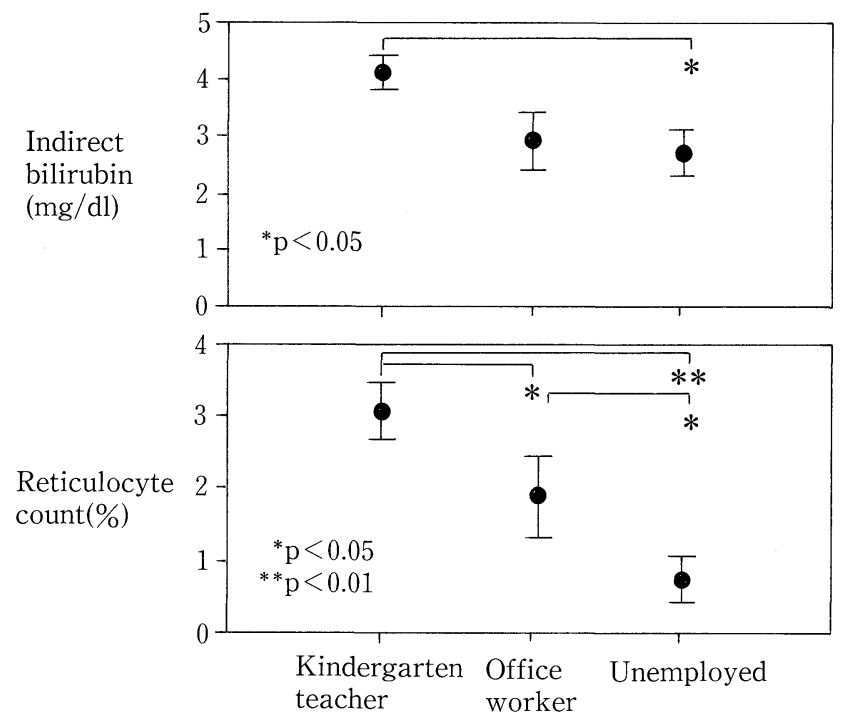

Figure 4. The patient's indirect bilirubin levels, reticulocyte count and CK levels, according to her occupational status. Each point represents mean $\pm S D$.

indirect bilirubin levels and reticulocyte counts according to her occupation. These levels decreased with the reduction of exercise according to her occupation.

\section{Discussion}

The clinical, laboratory and semiischemic forearm exercise test findings in the present case resemble those described in previously reported cases of muscle PFK deficiency $(1,10,11)$. The results of the bicycle-ergometer exercise test and biochemical analysis of erythrocytes were also similar to those previously reported $(3,12,13)$.

The genetic defect in this case has been reported by Hamaguchi et al (14). Polymerase chain reaction (PCR) amplification of the patient's cDNA revealed an in-frame truncation of 165 bases. This was compatible with the complete deletion of exon 19. The PCR amplified genomic DNA of the patient revealed a point mutation from $\mathrm{G}$ to $\mathrm{A}$ at the 5 'donor site of intron 19. Similarity of the human muscle type PFK (PFK-M) amino acid sequence to that of the rabbit PFK-M $(15,16)$ suggests that the truncated region involves putative ATP inhibition, fructose-6-phosphate binding and fructose-1,6bisphosphate binding sites corresponding to those of the rabbit PFK-M (17).

The presumed mechanism of hemolysis is a reduction of the cationic pump function in ATP-depleted erythrocytes, resulting in potassium leakage, calcium accumulation (18), a decrease in intracellular water, and an increase in intracellular viscosity. Murakami reported that membrane stiffness, which influences the deformability of erythrocytes, is modulated by the intracellular calcium content through the interaction between the calcium-calmodulin complex and cytoskeletal proteins (19). In the spleen, the $\mathrm{pH}$ of blood is relatively low (20), which further 
Phosphofructokinase Deficiency

Table 2. Hematological Data and Erythrocyte Phosphofructokinase Activity in Families

\begin{tabular}{lcccc}
\hline & $\begin{array}{c}\text { Hemoglobin } \\
(\mathrm{g} / \mathrm{dl})\end{array}$ & $\begin{array}{c}\text { Reticulocyte } \\
\text { count }(\%)\end{array}$ & $\begin{array}{c}\text { Total bilirubin } \\
\text { (indirect) }(\mathrm{mg} / \mathrm{dl})\end{array}$ & $\begin{array}{c}\text { PFK activity } \\
(\% \text { of control })\end{array}$ \\
\hline $\begin{array}{l}\text { Tarui et al, 1965, 1983 (1, 25) } \\
\quad \text { Elder brother }\end{array}$ & 15.7 & 5.2 & $1.0(0.6)$ & 30 \\
$\quad \begin{array}{l}\text { Younger brother } \\
\text { Sister }\end{array}$ & 13.9 & 6.5 & $2.9(2.2)$ & 48 \\
Waterbury et al, 1972 (26) & 14.1 & 2.2 & $0.9(0.6)$ & 42 \\
$\quad$ Grandmother & 11.9 & 0.6 & & 63 \\
$\quad$ Mother & 13.4 & 0.3 & & 55 \\
$\quad$ Son & 16.0 & 2.6 & $2.6(1.6)$ & 59 \\
Tani et al, 1983 (27) & 13.6 & 7.7 & $8.4(7.0)$ & 48 \\
$\quad$ Brother & 12.4 & 4.2 & $2.9(2.0)$ & 41 \\
$\quad$ Younger sister & 15.3 & 2.6 & $5.6(4.8)$ & 58 \\
\hline Present case & & & & \\
\hline
\end{tabular}

decreases the ATP level as well as the PFK activity (21). Therefore, in the cordal space of the spleen, erythrocyte deformity is markedly reduced, and the rate of hemolysis and phagocytosis of erythrocytes by cordal macrophages is accelerated.

In the present case, the increase of indirect bilirubin, reticulocyte count and erythropoietin without anemia indicates the presence of compensated hemolysis. The decrease of 2,3-DPG causes a shift to the left in the oxygen saturation curve and the decrease of $\mathrm{O}_{2}$ supply stimulates $\mathrm{O}_{2}$ sensors in the kidney; therefore the production of erythropoietin from the kidney is increased and the hemolysis is compensated.

In patients with muscle PFK deficiency, excess purine degradation occurs in the exercising muscles secondary to a defect of intramuscular glycogenolysis or glycolysis, inosine is readily metabolized in erythrocytes through the hexose monophosphate shunt, and the metabolism of erythrocytes is improved during and after exercise (6). In the present case, however, the hemolysis was improved when the patient was kept inactive in hospital and when she changed her occupation. It is suggested that exercise accelerated the hemolysis and rest improved it. It is speculated that the increase of ATP in erythrocytes due to exercise is temporary and insufficient to improve the hemolysis. These facts imply that factors other than erythrocyte metabolism may have played a role in the hemolysis.

In reports regarding families with muscle PFK deficiency (Table 2), the degree of hemolysis differs among patients with almost equal PFK activity in erythrocytes. The hemolytic symptoms were more severe in males than in females. This implies that sex and environmental factors may influence hemolysis in muscle PFK deficiency.

March hemoglobinuria is a rare hemolytic disorder and in its classical form the syndrome consists of hemoglobinemia and hemoglobinuria occurring in association with prolonged walking and running. Joshua and Vries reported exercise-induced shortening of the survival time of compatible normal red blood cells in the circulation of march hemoglobinuria patients (22). Lysolecithin is degraded from tissue cell-membrane phospholipids by the action of a phospholipase $\mathrm{A}_{2}$, and its concentration in blood plasma is increased during exercise $(23,24)$. It was reported that ATP-depleted cells or acidotic and $\mathrm{Ca}^{2+}$ loaded erythrocytes became more rigid when in contact with lysolecithin (23). In the present case, mechanical stress such as march hemoglobinuria or lysolecithin may be involved in hemolysis. It appears that the restriction of exercise will reduce the hemolysis and the muscle damage in muscle PFK deficiency, and we consider that this form of therapy should be attempted in nonspherocytic hemolytic anemia due to a disorder of the Embden-Meyerhof pathway.

Acknowledgements: We thank Dr. Takamichi Nishimura, Takao Shimizu and Hiromu Nakajima for their support in this work. This study was partly supported by a grant from the Gout Research Foundation of Japan and a grant from diabetes research from Otsuka Pharmacentical Co., Ltd.

\section{References}

1) Tarui S, Okuno G, Ikura Y, Tanaka T, Suda M, Nishikawa M. Phosphofructokinase deficiency in skeletal muscle. Biochem Biophys Res Commun 19: 517,1965 .

2) Kono N, Mineo I, Sumi S, Shimizu T, Kang J, Nonaka K, Tarui S. Metabolic basis of improved exercise tolerance; muscle phosphorylase deficiency after glucagon administration. Neurology (Cleveland) 34: $1471,1984$.

3) Mineo I, Kono N, Hara N, et al. Myogenic hyperuricemia. N Engl J Med 317: 75, 1987.

4) Kono N, Kuwajima M, Tarui S. Alternation of glycolytic intermediary metabolism in erythrocytes during diabetic ketoacidosis and its recovery phase. Diabetes 30: 346, 1981.

5) Chapman RG, Hennessey MA, Waltersdorph AM, Huennekens FM, Gabrio BW. Erythrocyte metabolism. V. levels of glycolytic enzymes and regulation of glycolysis. J Clin Invest 41: 1249, 1962.

6) Nortmann EA. Isolation of crystalline phosphoglucose isomerase from rabbit muscle. J Biol Chem 239: 1545, 1964. 


\section{TOYODA et al}

7) Bucher T, Pfleiderer G. Pyruvate Kinase from Muscle. in: Methods in Enzymology, Colowich SP, Kaplan NO Eds. Academic Press Inc, New York, Methods in Enzymology, 1995, p.435.

8) Bergmeyer HU, Gawehn K, Grassl M. Enzymes as Biochemical Reagents. in: Methods of Enzymatic Analysis, Vol. 1. Bergmeyer HU, Ed. Academic Press Inc, New York and London, 1974, p.423.

9) Tarui S, Kono N, Ueda K. Purification and properties of rabbit erythrocyte phosphofructokinase. J Biol Chem 247: 1138, 1972.

10) Layzer RB, Rowland LP, Ranny HM. Muscle phosphofructokinase deficiency. Arch Neurol 17: 512, 1967.

11) Kahn A, Etiemble J, Meienhofer MC, Bovin P. Erythrocyte phosphofructokinase deficiency associated with an unstable variant of muscle phosphofructokinase. Clinica Chem Acta 61: 415, 1975.

12) Kono N, Mineo I, Shimizu T, et al. Increased plasma uric acid after exercise in muscle phosphofructokinase deficiency. Neurology 36: 106, 1986.

13) Shimizu T, Kono N, Kiyokawa H, et al. Erythrocyte glycolysis and its marked alternation by muscular exercise in type VII glycogenosis. Blood 71: 1130, 1988.

14) Hamaguchi $T$, Nakajima $H$, Noguchi $T$, Ono $A$, Kono $N$, Tarui $S$, Kuwajima M, Matsuzawa Y. A new variant of muscle phosphofructokinase deficiency in a Japanese case with abnormal RNA splicing. Biochem Biophys Res Commun 202: 444, 1994.

15) Nakajima $H$, Noguchi $T$, Yamasaki $T$, Kono N, Tanaka $T$, Tarui $S$. Cloning of human muscle phosphofructokinase cDNA. FEBS Lett 223: 113, 1987.

16) Lee CP, Kao MC, French BA, Putney FC, Chang SH. The rabbit muscle phosphofructokinase gene. J Biol Chem 262: 4195, 1987.

17) Poorman RA, Randolph A, Kemp RG, Heinrikson RL. Evolution of phosphofructokinase-gene duplication and creation of new effector sites. Nature 309: 467, 1984.

18) Etiemble J, Kahn A, Boivin J, Bernard JF, Goudemand M. Hereditary hemolytic anemia with erythrocyte phosphofructokinase deñciency. Hum Genet 31: 83, 1976.

19) Murakami J. Changes of erythrocyte deformability induced by calcium accumulation and calmodulin inhibitors. J Physiol Soc Jpn 49: 119, 1987.

20) Murphy JR. The influence of $\mathrm{pH}$ and temperature on some physical properties of normal erythrocytes and erythrocytes from patient with hereditary spherocytosis. J Lab Clin Med 69: 758, 1967.

21) Tarui S, Kono N, Kuwajima M, Kitani T. Hereditary and acquired abnormalities on erythrocyte phosphofructokinase activity. Hemoglobin 4: $581,1980$.

22) Joshua $H$, Vries AD. Effect of exercise on red blood cell in march hemoglobinuria. Am J Clin Pathol 46: 341, 1966.

23) Shiraki K. The effect of splenectomy on sports anemia. J Physiol Soc Jpn 30: 1, 1968.

24) Rongausch $\mathrm{H}$. Influence of shape stabilizing agents on the deformability and morphology of lysolecitin-treated erythrocytes. Arzneim-Forsch/ Drug Res 38: 1478, 1988.

25) Shimizu T, Kuwajima M, Kono N, et al. Kinetic properties of mutant enzymes in erythrocyte phosphofructokinase deficiency and erythrocyte pyruvate kinase deficiency. Med J Osaka Univ 33: 49, 1983.

26) Waterbury L, Frenkel FP. Hereditary nonspherocytic hemolysis with erythrocyte phosphofructokinase deficiency. Blood 39: 415, 1972.

27) Tani K, Fujii H, Takegawa $S$, et al. Two cases of phosphofructokinase deficiency associated with congenital hemolytic anemia found in Japan. Am J Hematol 14: 165, 1983. 